\title{
Unusual Spontaneous Salmonella Peritonitis on Cirrhotic Decompensation: A Case Report
}

Raihane Bahri ${ }^{1,2^{*}}$, Hajar Saffour ${ }^{1,2}$, Saida Eddyb ${ }^{1,2}$, Fadoua Elfarssani ${ }^{1,2}$, Asma Amrani ${ }^{1,2}$, Nabila Soraa ${ }^{1,2}$

${ }^{1}$ Faculty of Medicine and Pharmacy, Marrakesh, Morocco

${ }^{2}$ Department of Microbiology, University Hospital Center Mohamed VI, Marrakesh, Morocco

DOI: $\underline{10.36347 / \text { sajp.2020.v09i12.005 }}$

| Received: 15.11.2020 | Accepted: 27.11.2020 | Published: 29.12.2020

*Corresponding author: Raihane Bahri

Abstract

Spontaneous bacterial peritonitis (SBP) is a common cause of morbidity and mortality in patients with advanced cirrhosis, while gram negative rods and Enterococcus species are the common offending organisms, Salmonella has also been recognized as a rare and atypical offending organism. Atypical features of Salmonella SBP include both its occurrence in cirrhotic patients with immunosuppressive state and its lack of typical neutroascitic response [1,2]. We report a case of culture-proven salmonella in a patient with decompensated cirrhosis, with low protein and without any underlying immunosuppression, and no other source to explain its origin.

Keywords: Spontaneous bacterial peritonitis; salmonella species; ascitic fluid protein, Marrakech.

Copyright $(\mathcal{C} 2020$ The Author(s): This is an open-access article distributed under the terms of the Creative Commons Attribution 4.0 International License (CC BY-NC 4.0) which permits unrestricted use, distribution, and reproduction in any medium for non-commercial use provided the original author and source are credited.

\section{INTRODUCTION}

Spontaneous bacterial peritonitis (SBP) is diagnosed on the basis of neutrophilic leukocytosis in peritoneal fluid. Antimicrobial therapy is initiated based on this finding pending isolation of organism. In some cases, bacteria may exist in peritoneal fluid in absence of neutrophilic leukocytosis (polymorphonuclear neutrophil $(\mathrm{PMN})<250 / \mathrm{mm} 3)$, a condition termed as monomicrobial non-neutrocytic bacteriascites (MNB). This is a poorly recognized clinical entity. Salmonella has been reported as an uncommon cause of SBP and is a rare microorganism to cause MNB. We report a rare case of Salmonella MNB and present a brief review of literature.

\section{CASE RePOrT}

A 69-year-old man was brought to the hospital by his son with confusion with painless abdominal distension.

The patient had recently recovered from a nonbloody diarrhea illness 4 days prior to presentation for which he did not receive any medical care. His past medical history was significant for cirrhosis secondary to hepatitis $\mathrm{C}$ diagnosed five years ago.

There was no fever, diarrhea, vomiting, or urinary symptoms but he was icteric and also had pedal edema, arousable with marked confusion, incoherent speech and inappropriate responses to questions.
Physical examination revealed blood pressure of $134 / 88$, heart rate of 140 beats per minute, respiratory rate of 26 breaths per minute. Chest auscultation showed regular heart beat with tachycardia, normal heart and breath sounds. Abdominal examination was notable for distension, non-tense ascites with diffuse tenderness on palpation. Initial laboratory tests were significant for hemoglobin 13.4 $\mathrm{g} / \mathrm{L}$, white blood cell count $6920 / \mathrm{mm} 3 \quad(60 \%$ neutrophils), platelets 153,000/mm3, ammonia 130mMol/L, ALAT 44 units/L, ASAT 150 units/L, ALP 182 units/L, total bilirubin $30 \mu \mathrm{mol} / \mathrm{L}$, TP $40 \%$ and $\mathrm{C}$ reactive protein $96,48 \mathrm{mg} / \mathrm{l}$.

Ultrasound sonography showed coarsened liver echotexture with irregular surface, enlarged spleen and ascites.

Initial ascitic fluid analysis results showed a leukocyte count of $680 / \mathrm{mm} 3$, majority being neutrophil $(60 \%)$ with BGN in coloration with Gram, protein at 20.4 Unit/l.

A diagnosis of SBP was suspected and the patient was admitted for diagnostic paracentesis and empiric antibiotics therapy.

However, 2 days later, ascitic fluid culture showed presence of Salmonella species, which was multi-sensitive. 
He was treated with an intravenous dose of ceftriaxone and also with lactulose for hepatic encephalopathy but had a poor response and he died four days later.

\section{DiscuSSION}

SBP is a common complication of patients with decompensated cirrhosis, with a mortality of up to $30 \%$.

Common offending organisms in SBP are Klebsiella pneumoniae, Escherichia coli, and Enterococcus species [3, 4], Salmonella Spp is a rare cause of SBP.

The antimicrobial (opsonic) activity in ascitic fluid depends on the protein content of the ascitic fluid, the level of immune defense of the host and the virulence of the organism. Low-protein ascitic fluids in cirrhotic patients are deficient in opsonic activity and are particularly predisposed to spontaneous bacterial peritonitis. It is thought that patients with normal or high protein levels appear to be protected from spontaneous bacterial peritonitis unless they are exposed to a particularly virulent organism such as Salmonella [5].

Total protein in the ascitic fluid in our patient was reported as $20,4 \mathrm{~g} / \mathrm{L}$. The fact that he had a diarrheal illness preceding presentation might have led to translocation of Salmonella into the peritoneum.

it is the ascitic fluid culture study that is the most important in identifying this unusual organism.
Since the empirical treatment with ceftriaxone seems to be the most efficient (as it is very active in vitro against salmonella and also against other common Enterobacteriaceae implicated in SBP).

\section{REFERENCES}

1. Runyon BA. AASLD Practice Guidelines Committee. Management of adult patients with ascites due to cirrhosis: an update. Hepatology. 2009; 49: 2087-107.

2. Fernández J, Del Arbol LR, Gómez C, Durandez R, Serradilla R, Guarner C, Planas R, Arroyo V, Navasa M. Norfloxacin vs ceftriaxone in the prophylaxis of infections in patients with advanced cirrhosis and hemorrhage. Gastroenterology. 2006 Oct 1;131(4):1049-56.

3. Evans LT, Kim WR, Poterucha JJ, Kamath PS. Spontaneous bacterial peritonitis in asymptomatic outpatients with cirrhotic ascites. Hepatology. 2003; 37(4):897-901

4. Haider S, Gupta R, Sood A, Kanitkar A, Saydain G. Monomicrobial Non-Neutrocytic Bacteriascites due to Salmonella enteritidis: A Case Report and Literature Review. Journal of Medical Cases. 2016 Jul 19;7(8):351-3.

5. Joseph T, Sobhan P, Bahuleyan S, John A, Abdul Sathar S, Sreesh S, Vinayakumar KR. Nontyphoidal salmonella: an unusual cause of spontaneous bacterial peritonitis in decompensated cirrhosis. Gastroenterology report. 2014 Aug 1;2(3):242-4

6. Fernández J, Navasa M, Gómez J, Colmenero J, Vila J, Arroyo V, Rodés J. Bacterial infections in cirrhosis: epidemiological changes with invasive procedures and norfloxacin prophylaxis. Hepatology. 2002 Jan;35(1):140-8. 